\title{
REVIEWS
}

NURSING PRACTICES IN INDUSTRY

U.S. Public Health Bulletin No. 283

By Olive M. Whitlock, Victoria M. Trasko and F. Ruth Kahl

(U.S. Government Printing Office, Washington. 1944. Pp. 70.5 cents.)

In the United States in 1943 over 12,000 nurses were employed full-time in industry.* This number was a very great increase over previous years, because of the war. In 1941, for example, the number was over 6000 , and in 1930 about 3000 . Nursing service in industry has developed, as in Great Britain, according to the interest and vision of industrial medical officers and managements, but with few recognized standards. So a survey by means of a questionary was carried out by the Government's Public Health Service with a view to obtain factual data of the nurses' work. The report based on this survey discusses various problems that arise, and also makes recommendations for the future. The survey was conducted (in 36 States) during 1942 in 924 establishments employing some $2 \frac{1}{2}$ million workers, and covering the activities of over 3000 full-time nurses, a number of part-time nurses, and a number of " nonprofessionally trained workers.'

The duties performed by nurses fell into 8 categories. (The percentage of plants carrying out these activities is given in brackets.)

(1) Routine organization and maintenance of the medical department, including care of the ambulance room, purchase and preparation of supplies, keeping of sick records and preparation of reports. (100 per cent.)

(2) Treatment and care of occupational injuries and illnesses, and emergency care of non-occupational conditions. (100 per cent.)

(3) Assistance with medical examinations. (50 per cent.)

(4) Health education, including meetings with workers, distribution of health literature, follow-up of remediable defects, and teaching of home nursing classes. (15 per cent.)

(5) Assistance with safety education and accident control, which included serving on safety committees, teaching first aid, and duties concerned with the care and distribution of personal safety equipment. (42 per cent.)

(6) Assistance with environmental sanitation, including inspection of ventilation, lighting, plant housekeeping, and sanitary arrangements for women workers. (39 per cent.)

(7) Participation in welfare matters, including personal advice to workers, assistance with canteen management and sick benefits. ( 75 per cent.)

(8) Provision of a home nursing service, mainly to find out causes of absence, to determine elegibility for benefits, to assist the worker with social problems, or to give nursing care to the ill or injured. (25 per cent.)

In addition, in 14 per cent. of 868 plants surveyed, industrial nurses were found to have other activities not requiring nursing skill such as typing, relieving in the canteen or at the switch-board, personnel work, checking pay-rolls and photographing and finger print impressions. At the same time in many of these cases departments such as personnel and safety were performing health functions which should have been delegated to the medical department. The report points out that confusion arose as a result of this. It also points out that the nurse in the small plant is likely to have a greater variety of duties than her colleague in a large concern.

In discussing the various problems arising out of this extensive survey the authors make the following points. No rigid outline of duties can be laid down because of the diverse needs of industry, but certain principles can be applicable in all cases. There is much need for special training and * Based on returns from the 1943 National Survey of Registered
Nurses, with the addition of figures secured from the rosters of inNurses, with the addition of figures secured from the rosters of in-
dustrial nurses maintained by the various State nursing consultants. education for industrial nurses. Standing orders or written procedures for industrial nurses should be laid down by the medical profession. There is need for more and better supervision of the nursing service. Generally speaking the nurse has inadequate appreciation of the need for and use of records. Much time is taken up in non-nursing duties, thus causing wastage of trained personnel especially during the war emergency. While non-professional attendants are useful because of the shortage of nurses, they should be more adequately supervised.

On completion of the survey the advisory committee set up to deal with these problems made a large number of recommendations the more important of which are as follows. Nurses working without the direction of a full-time physician should have written standing orders. Where no doctor is responsible for the medical service the nurse should receive her standing orders from the Committee on Industrial Health of the County Medical Society. Nurses assisting at medical examinations save the time of the physician and are of the greatest value. The nurse's part in this should be limited to the taking of personal occupational histories previous to examination; doing routine tests and explaining their significance; taking specimens for serological and other laboratory examinations and explaining their significance; telling the worker about the management's health and welfare policy; making periodic inspections for symptoms and indications of occupational disease; interviewing employees on their return to work after sickness and injury.

The nurse should take part in the firm's health education programme, and assist with accident prevention. She should assist with plant sanitation and should know the various legal requirements relating to lighting, ventilation, cleanliness, sanitary provisions, etc. While the report does state that direct responsibility for industrial hygiene should be delegated to other departments wherever possible, it makes no mention of the nurse's limitations in this respect. There is not enough emphasis on the fact that industrial nursing is only a part of industrial medicine, and that in all her work the nurse should be responsible not directly to management but to a medical officer.

Home nursing service should be provided by the firm This is another important difference between industrial nursing in the U.S.A. and in Great Britain. While in certain cases sick visiting by nurses is undoubtedly part of medical supervision in industry in this country there are definite limits to which the nurse should go in the interests of the patient, and for ethical reasons. There is no mention in this report of the vital importance of the general practitioner service and the link that it should have with industrial medicine. It would have been interesting, too, to know something of the methods by which American nurses are to be trained for industrial work and the part that the medical profession is taking in this. However, the report is of much interest to industrial medicine and should have wide publicity.

D. $\mathbf{S}$.

\section{ANSWERS TO INDUSTRIAL HEALTH AND SAFETY PROBLEMS}

\section{By Jack E. Weiss}

(Cleveland, Ohio. 1944. Pp. 699. £3 1s. 6d.)

Already some American manufacturers view industrial health and safety with a new gleam in the corporate eye. They see profits; they have come to realize that unhealthy and unsafe working conditions cost them money. This is the motif of this book, dedicated to 